\title{
PARTicipaÇão efetiva COM ReCURSo A NARRATIVAS NEGOCIADAS
}

\author{
Anna Zaluczkowska \\ The Northern Film School, Universidade Leeds Beckett, Reino Unido
}

\begin{abstract}
Resumo
Este artigo analisa o projeto "Red Branch Heroes", um protótipo interativo e transmédia, lançado na Irlanda do Norte. Este projeto de investigação ação analisa as técnicas de escrita que podem ser utilizadas para promover uma participação eficaz. $O$ artigo sugere uma forma de participação que reconhece os equilíbrios de poder que existem entre o autor e as audiências em narrativas digitais. Defende uma série de técnicas que promovem uma maior partilha desse poder, para que essas posições de poder sejam desafiadas. Mas também defende o papel do autor como o de um condutor ou orquestrador, papel este que é definido por um processo de negociação. Tal processo resulta numa "narrativa negociada".
\end{abstract}

Palavras-Chave

narrativas; participação; storytelling; transmédia interativos; websérie

\section{MEANINGFUL PARTICIPATION VIA NEGOTIATED NARRATIVES}

\begin{abstract}
This article analyses the project "Red Branch Heroes", an interactive, transmedia prototype that was set in Northern Ireland. This piece of practice based research investigates the writing techniques that can be used to promote useful participation. The article suggests a form of participation that acknowledges the power balances that exist between author and audiences in digital narratives. It advocates a range of techniques that promote a greater sharing of that power so that those power positions are challenged. But it also advocates for the role of author as one of conductor or orchestrator, a role that is defined by a process of negotiation. Such a process results in a "negotiated narrative".
\end{abstract}

\section{KEYWORDS}

interactive transmedia; narratives; participation; storytelling; web series

\section{INTRODUÇÃo}

O "Red Branch Heroes" (RBH), um protótipo de projeto lançado na Irlanda do Norte e desenvolvido por uma equipa composta por três pessoas, incluindo o autor deste artigo, consiste numa performance, por um lado, e num jogo, por outro. Este jogo utilizou websites, redes sociais, jogos e produção de vídeo ficcional para contar uma 
estória, bem como músicas, livros de banda desenhada, reportagens fotográficas e uma variedade de outros média. Neste sentido, considera-se este exemplo como um projeto transmédia interativo. Este termo tem sido aplicado a produções em grande escala de Hollywood e a projetos artísticos autofinanciados de pequena dimensão (Dena, 2009, p. 4), enquadrando-se o projeto $\mathrm{RBH}$ nesta última categoria.

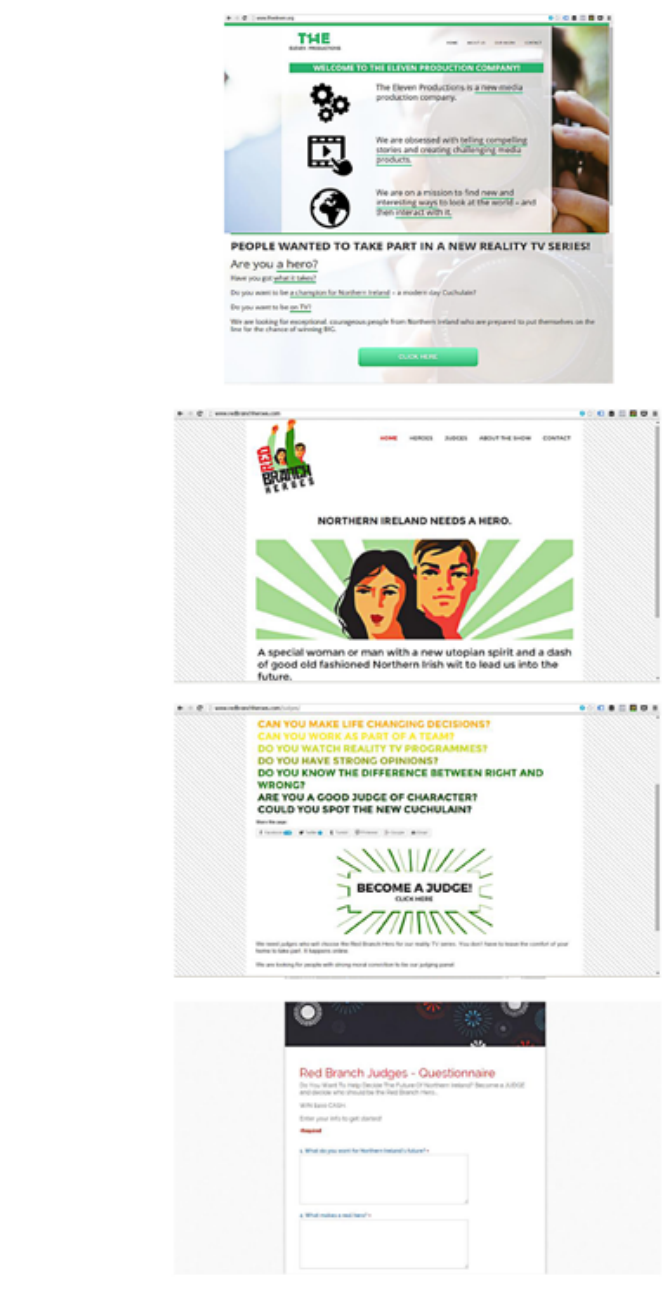

Figura 1: Website do projeto

Fonte: http://www.redbranchheroes.com/ e http://www.theeleven.org/

Muitos criadores de transmédia sugerem que as formas de participação são cruciais para o seu sucesso (Gomez, 2011; Jenkins, 2006; Phillips, 2012), mas é habitual os programas atualmente disponíveis oferecerem apenas enredos preestabelecidos, orientados pelo autor, desapontando assim as audiências (Manovich, 2001; Rose, 2012; Ryan, 2001). O protótipo RBH e a metodologia de investigação-ação prática associada analisou tanto os processos de escrita utilizados, como o papel que essas práticas de storytelling poderiam desempenhar em sociedades pós-conflito, como a Irlanda do Norte.

O projeto foi lançado na Irlanda do Norte, um local onde o capital social desta sociedade se articula com um vibrante espaço público que valoriza a participação. Esta situação é demonstrada pelas diversas organizações culturais, desportivas e de 
voluntariado que aí existem atualmente. A família e a comunidade continuam a ter uma importância considerável. Contudo, a relação entre esta sociedade e as instituições políticas apresenta muitas tensões (Coulter \& Shirlow, 2019; Dawson, 2019; McQuaid, 2012).

$\mathrm{O}$ projeto $\mathrm{RBH}$ visava contribuir para as discussões existentes sobre storytelling no contexto da Irlanda do Norte e o papel que o storytelling/a participação podem ter na reconstrução e reconfiguração dessa sociedade, ou de qualquer outra sociedade pós-conflito. Muitos sugerem que o storytelling é uma forma de as pessoas perceberem e representarem o seu mundo, de o desconstruírem e reconstruírem (Berger, 1979; Zipes, 2011). Outros académicos foram mais longe e sugerem que as histórias têm um efeito mais amplo e podem transformar sociedades (Arendt, 1958; Gomez, 2011; McGonigal, 2011). Le Hunte e Golembiewski sugerem no seu resumo que

os humanos colocam-se a eles mesmos nas histórias, enquanto observadores e participantes, para criarem um "equilíbrio neural" ou ponto ideal que lhes permita estarem imersos numa história sem serem totalmente ameaçados por esta - e este envolvimento na história leva à formação de empatia - uma empatia que é parte integrante da formação de uma humanidade futura. Defendemos que é através da empatia que as histórias têm o poder de nos salvar. (Le Hunte \& Golembiewski, 2014, p. 1)

Muitos projetos de storytelling na Irlanda do Norte fazem questão de utilizar esses traços empáticos. No entanto, consideramos que o storytelling na Irlanda do Norte (ou em qualquer contexto transmédia ou interativo) ainda não tem o poder de mudar radicalmente uma determinada sociedade. Em vez disso, defendemos que essas práticas nos oferecem uma forma de repensar o nosso mundo em conjunto, através de contos novos e antigos, e de contar coletivamente essas histórias com formas novas e imersivas, que nos ajudam a aprender e compreender as nossas esperanças e aspirações em relação ao futuro. Estas práticas também nos permitem repensar e reconfigurar a participação, passando para relações de poder mais equilibradas.

Este artigo analisa o $\mathrm{RBH}$, dando especial atenção às suas dinâmicas participativas e à forma como as técnicas de design promovem uma maior partilha de poder criativo. $\mathrm{O} \mathrm{RBH}$ é visto como um desafio às posições tradicionais de autor e de leitor, que passam a estar em colaboração para criarem uma narrativa negociada. O seu trabalho criativo é caracterizado por uma liminaridade que não só contribui para a transformação do conflito, mas também permite a promoção de uma multiplicidade de vozes, o que confere ao projeto uma vertente intrinsecamente democrática. $\mathrm{O}$ RBH não é produzido apenas por comunidades imaginadas, ainda que apoie a criação dessas mesmas dinâmicas, demonstrando, uma vez mais, as capacidades socialmente benéficas da participação. Além disso, o posicionamento protetor dos autores - a equipa do projeto - revela-se como uma forma de mediação contra os aspetos negativos da participação online, conhecida como dark participation. 


\section{"Red Branch Heroes"}

$\mathrm{O} \mathrm{RBH}^{\prime}$ consiste num projeto que encorajava os participantes a tornarem-se jurados num projeto ficcional de reality TV (que desafiou as convenções da reality TV) tendo como objetivo a eleição de um novo "herói" para a Irlanda do Norte. Foram apresentados aos jurados diversos objetos que pertenciam a personagens fictícias, sendo-lhes pedido para fazerem perguntas durantes essas apresentações, de forma a perceberem quem poderiam ser essas pessoas. Esta interrogação foi utilizada pelos autores/empresa de produção (entre os quais se incluíam, como referido anteriormente, o autor deste artigo) como um feedback loop para ajudar a criar personagens e história para uma websérie. Os principais participantes na produção são apresentados na Figura 2, mas houve uma consulta muito mais ampla sobre o projeto em toda a Irlanda do Norte.

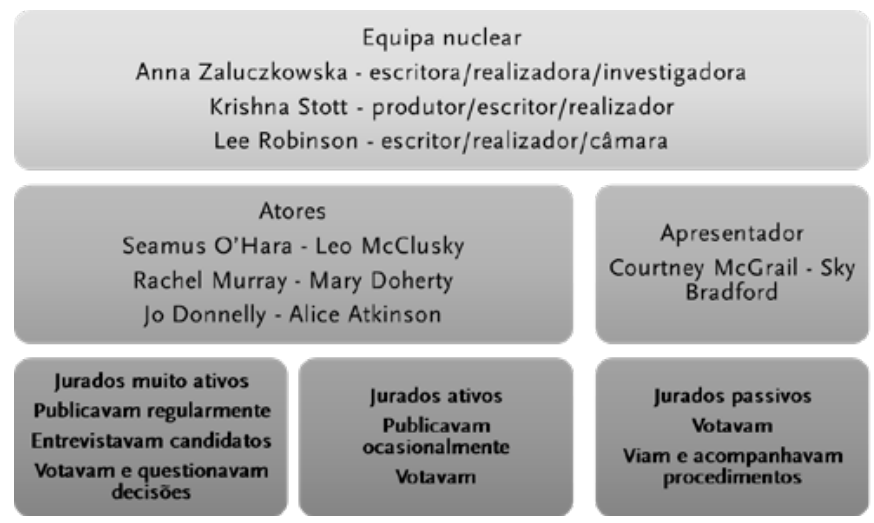

Figura 2: Participantes no projeto

Para dar um exemplo do desenvolvimento de personagens: a personagem Mary Doherty apresentou o conteúdo da sua bolsa para que os jurados analisassem. A partir daí, começaram a pensar em quem ela poderia seria e qual a aparência que teria. À medida que faziam as suas observações através de uma aplicação num chat, os autores viam e inseriam estas informações no perfil da personagem Mary, divulgando mais informações sobre ela sob a forma de imagens, perfis psicológicos e citações da personagem, que refletiam as opiniões dos jurados. O feedback loop ajudou a criar, aprofundar e consolidar as personagens. Foi, depois, pedido aos jurados que votassem na sua personagem preferida, tendo sido escolhidas três para serem desenvolvidas com mais detalhe. Desta vez, os jurados puderam ficar a conhecer as suas criações cara a cara enquanto se selecionavam atores para as interpretar. Os jurados entrevistaram estes "candidatos" e acabaram por utilizar estas informações para decidirem quem iriam promover para o mundo exterior como um "herói" apropriado para a Irlanda do Norte. O público, amigos e familiares votaram, em seguida, no seu candidato preferido. A personagem Leo acabou por ser a escolhida como o "herói" e seria a primeira a surgir na websérie proposta.

'Estão disponíveis mais informações sobre o RBH em http://www.redbranchheroes.com/phd/practice/ 


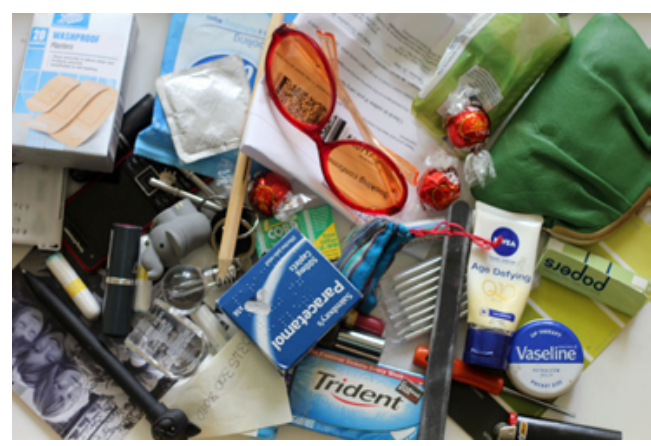

Figura 3: Candidatura de Mary Doherty Fonte: Bellyfeel/Autor

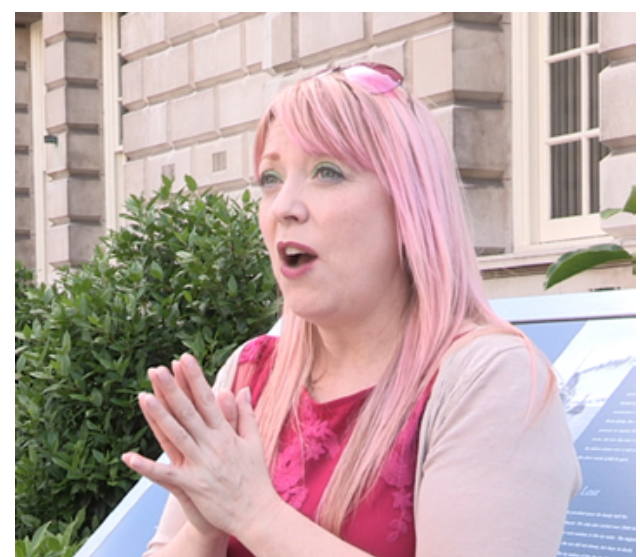

Figura 4: Mary interpretada pela atriz Fonte: Bellyfeel/Autor

Os sítios eletrónicos do $\mathrm{RBH}$ foram pensados para serem utilizados principalmente em smartphones e tablets ${ }^{2}$. Contudo, como nem todas as pessoas têm acesso a um smartphone, a participação restringiu-se, desde logo, a quem tinha. A disponibilidade de banda larga constituiu também uma questão, tendo havido muitas pessoas a queixar-se sobre o acesso limitado ao projeto. A equipa do projeto também percebeu que precisava de pessoas para participar no projeto e estudar a forma, o que tornou os incentivos externos importantes, com vista a motivar a participação, tendo de ser aplicados de forma adequada. Oferecemos uma recompensa financeira ( $£ 100$ para o melhor participante) pela participação e deixámos claro de que se tratava de um projeto sem fins lucrativos e em propriedade comum.

\footnotetext{
${ }^{2}$ Apesar de a razão principal para lançar o projeto na Irlanda do Norte estar associada à herança do conflito conhecido como "The troubles", os níveis de posse de tablets e de utilização de smartphones indicaram que a Irlanda do Norte era um local eficaz para conduzir uma experiência em linha. Segundo o recente relatório Communications market report: Northern Ireland, da OFCOM (2013), a Irlanda do Norte apresenta uma das maiores taxas de adesão a tablets no Reino Unido. Este relatório também demonstra que as redes sociais continuam a ser populares, com $53 \%$ da população da Irlanda do Norte a aceder ao Facebook, Twitter e outros serviços em linha semelhantes (Amostra do estudo: adultos com idade superior a 16 anos que utilizam a internet em casa ou noutros locais, $n=376$, Irlanda do Norte 2013).
} 
Enquanto projeto online, o RBH funciona num contexto global que Shoshana Zuboff (2018) designou por The age of surveillance capitalism. O RBH utilizou reconhecidamente um tipo de prática de vigilância para criar as suas histórias. Contudo, é um tipo que é reconhecido e apoiado pelos seus utilizadores, assentando num processo de reconhecimento e negociação, concebido para encontrar uma abordagem mutuamente acordada de construção de uma história que tem por base a internet e é democrática. Em vez de afirmar "a nossa experiência privada está disponível para quem quiser, que se traduz em dados para a sua posse privada" (Zuboff, 2019, p. 19), a equipa alertou os nossos jogadores para os desequilíbrios de poder em jogo, para que todos pudessem envolver-se num diálogo, através de um projeto gamificado. Assim, este artigo é necessariamente uma tentativa de contribuir em parte para o que Quandt (2018, p. 44) define como "uma agenda futura" de investigação sobre a participação, em que são consideradas ambas as perspetivas positivas e negativas deste conceito. Sugere que a investigação "deve aceitar e incluir ambas as perspetivas, positivas e negativas, e precisa de oferecer referências mais claras sobre a relevância para a sociedade de ambos os fenómenos e de tudo o que estiver entre eles".

Zuboff e Quandt não são os únicos a sugerir que a participação em linha pode ter consequências negativas. Por exemplo, Lutz e Hoffman escrevem que

a criação de conteúdos online pode, no entanto, ser associada a importantes desvantagens individuais e coletivas. Os utilizadores podem ficar associados a causas que não apoiam. A participação pode incitar a confrontação, disputa, incivilidade, difamação, bullying, repressão e perseguição online. (Lutz \& Hoffman, 2017, p. 877)

Num ambiente pós-conflito como a Irlanda do Norte, a equipa deste projeto estava apreensiva com o "lado negro" da participação, mas consciente de que a participação poderia ter consequências imprevisíveis. Fizemos questão de encontrar um contexto de escrita que pudesse lidar com essas ocorrências e minimizar o conflito. Neste sentido, caímos na armadilha que Quandt (2018), e antes dele Cooke e Kothari (2001) e Miessen (2010), identificaram: a nossa investigação sobre a participação focou-se em atos observáveis de criação de conteúdos e, de certa forma, ignorou o contexto mais geral, os limites que impôs às práticas de participação sob escrutínio e a falta de participação neste mesmo contexto mais geral. Contudo, questionámos posteriormente esta posição e analisámos a motivação dos utilizadores e a qualidade dessa participação quando não foi conseguido um grande número de participantes para testar o trabalho. Como tal, tivemos em conta a participação que aconteceu, mas também a que não aconteceu. Muitos dos resultados deste projeto foram positivos, mas neste artigo chamamos a atenção para a falta de uma maior participação e a forma como a participação negativa ou disruptiva é mediada nos processos de design utilizados.

Enquanto protótipo, o $\mathrm{RBH}$ pode ser considerado um teste tecnológico de baixa fidelidade que desenvolveu ferramentas simples para explorar a ideia de uma Irlanda do Norte futura e idealizada. Neste sentido, pode ser visto como semelhante à dos estudos 
em que se usa o "diário de campo" para recolher informação através dos participantes. Madden, Cadet-James, Atkinson e Watkin Lui (2014) escrevem sobre este instrumento de recolha de informação via participantes e protótipos que visam criar um design culturalmente apropriado ao bem estar individual. Gaver, Dunne e Pacenti (1999) desenvolveram a ideia de utilizar "sondas culturais" para explorar o design para pessoas mais velhas. Os kits de registo de informação, geralmente compostos de média de natureza diversa, que são dados aos participantes, constituem ferramentas simples e flexíveis que permitem aos designers conhecer os potenciais utilizadores. Desde então, esses tipos de instrumentos têm sido utilizados para inspirar o design, aumentar a participação e construir e promover o diálogo. Esta técnica também tem sido usada no contexto tecnológico (Mattelmaki, 2005) na forma de aplicações de baixa fidelidade utilizadas para reunir informação sobre a utilização de TIC e o ambiente dos participantes para inspirar um aprofundamento do design. Foram identificados problemas:

vemos, cada vez mais, este tipo de registo tecnológico a ser utilizado não num sentido de inspiração, mas como forma de gerar requisitos funcionais para determinar o melhor caminho a seguir. De facto, vemos este aspeto como uma das formas em que as "sondas tecnológicas" se desviam do design padrão usado nas "sondas culturais". (Madden et al., 2014, p. 42)

Em geral, os participantes não estavam especialmente interessados na mecânica da escrita, mas demonstraram ter interesse em participar em algo que contribuísse para uma Irlanda do Norte melhor. Essas ambições foram identificadas pelos próprios participantes em questionários realizados antes e depois do projeto, mas não era objetivo do projeto concretizar todas essas aspirações. Era, pois, importante que as expectativas fossem geridas desde o princípio. Por este motivo, o nosso sítio na internet incluía uma secção que explicava em que consistia o projeto e em todos os questionários enviados constava uma história pessoal do nosso trabalho que demonstrava a nossa abordagem. Algumas pessoas terão sido dissuadidas por esta informação. Contudo, conseguimos deixar claro que o objetivo não era utilizar a participação da comunidade para o desenvolvimento de um negócio ou para obter ganhos económicos, mas para testar e reagir a circunstâncias locais num ciclo contínuo de exploração e improvisação. Deste modo, a investigação evitou os perigos funcionais identificados, utilizando uma combinação entre design participativo e investigação-ação participativa para criar uma narrativa negociada (ver abaixo). Essas preocupações limitam, contudo, o número de pessoas que participam e o tipo de participação que pode ser obtida. A necessidade de esclarecermos os nossos objetivos destruíram muitas das técnicas imersivas habitualmente utilizadas para envolver as pessoas em trabalhos ficcionais e, como resultado, o número de participantes foi baixo. O feedback obtido também indica que a nossa necessidade de recolha de dados constituiu uma importante barreira à participação quando as pessoas tinham de preencher formulários e fornecer detalhes pessoais. Esses fatores seriam minimizados caso o trabalho fosse mais desenvolvido. 


\section{UMA NARRATIVA NEGOCIADA}

O protótipo $\mathrm{RBH}$ indica que escrever para transmédia interativos é um processo que tem de colocar em primeiro plano os interesses do leitor/audiência e que o papel do autor poderá ser semelhante ao de um condutor ou orquestrador. Tal assemelha-se à conceção de Barthes, de autor como scriptor, uma pessoa que produz o trabalho. Contudo, no $\mathrm{RBH}$, os leitores contribuem ativamente para o guião e para o processo de produção do texto através da sua própria participação, pelo que também produzem o trabalho. Sugerimos que tanto os leitores como os autores sejam scriptors e leitores neste contexto, apesar de caber ao autor uma maior responsabilidade pela qualidade do texto final. Este trabalho é elaborado, como Barthes sugere, a partir de "inúmeros centros de cultura" (Barthes, 2001, p. 210) e não a partir de uma experiência individual. Apesar de a imersão ser comum a todas as formas de texto, é alcançada uma experiência diferente de imersão neste contexto de transmédia interativos ao ser adotada uma abordagem gamificada das narrativas ficcionais (Alderman, 2015). Através do que Jenkins designa de "cultura da convergência" (2006), e agora mais comummente através de tecnologia convergente como os smartphones, as pessoas conseguem entrar no mundo real da história e agir. A improvisação desempenha um papel central neste tipo de processo de escrita (Millard, 2014), embora ainda não estejam totalmente desenvolvidas formas de prática colaborativa para facilitar essa participação efetiva.

É a liminaridade da forma e da situação que torna a participação tão crucial neste contexto. A forma transmédia/interativa precisa de liminaridade, uma ambiguidade em que o leitor/utilizador está num processo de mudança ou desorientação em que a hierarquia habitual entre autor e leitor é invertida. Uma certa liminaridade em várias formas diferentes também é oferecida pelas diversas plataformas e métodos utilizados, nos quais a ordem habitual da escrita é perturbada. A Irlanda do Norte é uma sociedade que está a passar por um processo específico, embora não único, de transição e estagnação - muitas vezes designado por "pós-conflito" - pelo que defendemos que essa liminaridade exige a adoção de uma narrativa construída a partir das várias vozes envolvidas na sua construção e que inclua ativamente elementos discursivos: por outras palavras, um discurso3.

Para construirmos este argumento, podemos regressar à crítica da Escola de Frankfurt, que demonstrou insatisfação perante as implicações culturais e políticas dos média durante o século XX. Jürgen Habermas (1991) sugeriu que as indústrias do século XX tinham métodos sofisticados de persuasão que destruíram o diálogo entre pares. Esta corrente de pensamento apresentou também uma crítica do público enquanto audiência de massa, manipulada por métodos de comunicação. Reconhecemos que muitos dos teóricos que trabalhavam esta crítica escreviam à sombra do Third Reich e mostravam-se preocupados com a poderosa distribuição de propaganda na imprensa, rádio e cinema. Na verdade, na cultura contemporânea percebemos de que forma é que os métodos transmédia poderiam ser utilizados de forma eficaz com objetivos de propaganda

\footnotetext{
${ }^{3}$ Falamos aqui de discurso no sentido pós-moderno do termo, especificamente o de Foucault $(1977,1980)$, que defende que
} o poder está sempre presente na comunicação, produzindo "verdades", mas também os seus limites e condicionalismos. 
semelhantes, mas questionamos a ideia de ver as audiências como participantes desinformados ou passivos. De facto, muito desse comportamento passivo é atualmente contestado na "fan culture" e em estudos de audiência (Abercrombie \& Longhurst, 1998; Jenkins, 2012). Ao passo que algumas audiências se contentam em ver e consumir, existe um número cada vez maior que pretende aparecer.

Esta observação foi confirmada pela nossa investigação, não só pela maneira como as pessoas queriam aparecer no projeto, mas também pela forma como as pessoas faziam questão de dar informações que contribuíram para a construção do projeto. No entanto, o protótipo poderia ser considerado eficaz no desenvolvimento de um consenso neoliberal em relação à vida cívica na Irlanda do Norte. Por esta razão, defendemos que o papel do autor é tão importante como o papel do leitor nesta forma de transmédia. $O$ papel de um não se sobrepõe ao do outro. O autor tem a responsabilidade de preparar um pré-texto, um termo do "process drama" para designar determinado "local" dramático, "um mundo ficcional que será habitado pelas visões, interpretações e compreensões que poderá gerar" (O'Neill, 1995, pp. 12-13). O debate em linha e a construção da história acontece dentro deste mundo dramático. Compete ao autor estar ciente das implicações desta dinâmica e aos leitores estarem conscientes das perspetivas e intenções desse autor, se o elemento do discurso for totalmente mantido ao longo do projeto.

Barthes conclui que "sabemos que para que a escrita tenha futuro, é necessário reverter o mito: o nascimento do leitor deve pagar-se com a morte do Autor" (2001, p. 213). Mesmo tendo em mente que esta reversão é mais complexa do que parece, e que Barthes é tão cético em relação ao leitor como em relação ao autor, o seu trabalho é útil, porque sugere que tanto o leitor como o autor devem desempenhar papéis iguais em relação ao texto. Contudo, no $\mathrm{RBH}$, o autor renasce continuamente apenas para morrer de novo. Neste contexto de transmédia, o leitor está numa posição semelhante, partilhando parte do papel de scriptor. Neste sentido, é obtida maior paridade ou poder entre o autor e o leitor. A relação entre o autor e o leitor é crítica nesse contexto, dada a natureza colaborativa do projeto, bem como a confiança e empatia que este tipo de produção exige.

Os leitores/participantes estavam constantemente a tentar avaliar que propósito e significado implicava o pré-texto e as informações apresentadas, pelo que a afirmação de Barthes de que o autor está morto é ligeiramente problemática neste caso. No início, era importante que a audiência soubesse quem era o autor e o que estava a motivar a sua prática. Sem este conhecimento (que adquirimos na Irlanda do Norte dentro de uma comunidade específica), a negociação teria sido baseada na suspeição e poderia resultar em conflito. Na Irlanda do Norte, onde as noções de território são frequentemente disputadas, a ideia de um projeto negociado - aquele que é construído por um conjunto de pessoas, tanto profissionais como não profissionais - abre possibilidades à transgressão das fronteiras definidas. 


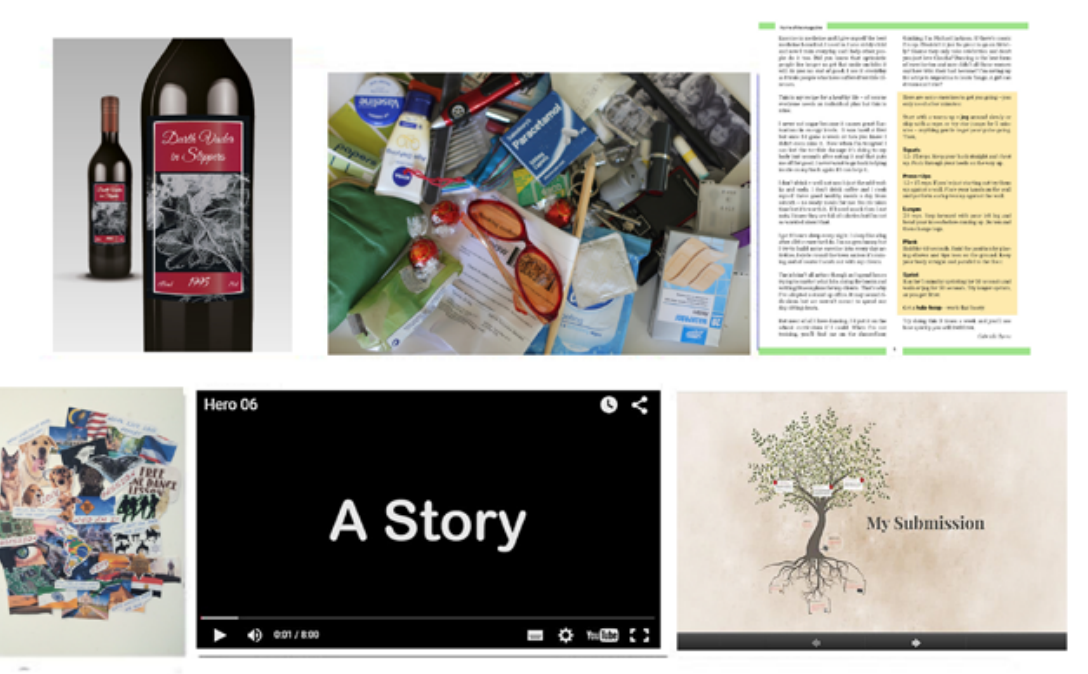

Figura 5: Apresentações dos candidatos Fonte: Bellyfeel/Autor

Tony Watson (2001) utilizou o termo "narrativa negociada" em relação à educação e aprendizagem da gestão crítica - mais especificamente, às formas de ensinar e construir práticas de gestão. Utiliza o termo (que, por sua vez, pediu emprestado aos estudos literários) para sintetizar um conjunto de "histórias" no processo de gestão (a história do praticante, a história da investigação académica e a história da teoria) para descobrir "a história por detrás da história" (Watson, 2001, p. 388). Adaptámos e utilizámos este conceito para inferir uma síntese de histórias (propostas pelos jurados, por pessoas da Irlanda do Norte, de mitos, teorias da escrita e reformulações de outros escritores), mas, no $\mathrm{RBH}$ esta síntese resulta na criação de uma narrativa nova e negociada, que reflete a "história por detrás da história".

Numa narrativa negociada, a narrativa está constantemente a mudar devido às negociações, pelo que a utilização deste termo implica um conceito em evolução e não uma posição fixa. Além disso, utilizamos o termo "narrativa" de forma fluida, não só para nos referirmos à ação que acontece no projeto e à transformação que resulta dessa ação, mas também para abranger as intervenções e interrupções que são causadas nas fases de negociação do projeto. Tal envolve necessariamente elementos discursivos e experimentais que, geralmente, não farão parte de um texto narrativo, mas que são comummente utilizados em instalações artísticas e em projetos de artes digitais. A narrativa negociada no $\mathrm{RBH}$ reconhece que o processo de criação e o seu impacto emocional é tão importante para a criação da performance online quanto as histórias fundidas que contribuirão para o produto final. As regras estéticas dessa narrativa assemelham-se mais a jogos de construção de mundos, como The Sims, do que a literatura para filmes e televisão. Ser interativo ou participar neste projeto exigiu a necessidade de criar uma ligação direta entre a audiência e o criador; uma comunicação que tem potencial para informar ou afetar o processo de desenvolvimento criativo. 


\section{COMUNIDADES IMAGINADAS}

O carácter interativo do projeto constituiu uma oportunidade para interagir (participar) com audiências de diferentes comunidades, construindo ambientes ficcionais seguros que as audiências poderiam preencher para criar "comunidades imaginadas" (Anderson, 1983), que apresentam oportunidades de comentário e colaboração, abrindo possibilidades para o futuro no mundo real. Apesar de a expressão de Anderson ter sido criada para se referir especificamente ao nacionalismo, atribuindo a propagação deste ao desenvolvimento e crescimento da imprensa, utilizamos o termo de uma forma mais abrangente (referindo-nos a uma comunidade de interesses, também na aceção de Said (1978) de "geografias imaginadas") para destacar elementos que podem ser criados a partir de uma investigação de características presumivelmente acordadas. Estas características presumíveis foram definidas por quem respondeu aos nossos questionários e participou na nossa história.

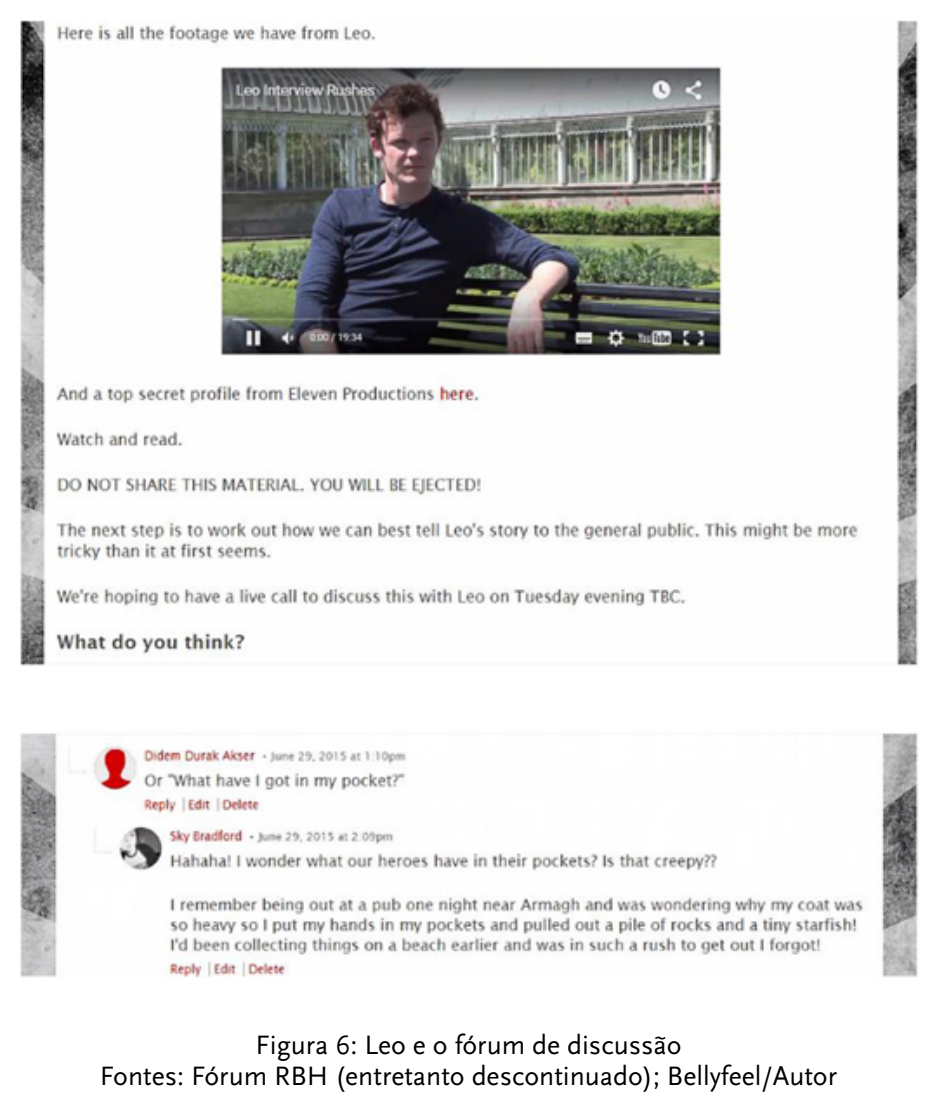

Contudo, o termo também é eficaz para referir os atributos "imaginados" ou "percecionados" que são facultados pela internet, podendo tanto referir-se aos elementos utópicos como nacionalistas que aí são representados. O projeto forneceu o exemplo seguinte em que a criação de uma personagem online através de feedback loop poderia ser considerada problemática no contexto da Irlanda do Norte. O Leo forneceu uma reportagem fotográfica da sua zona local como objeto de candidatura (ver Figura 6) e, ao fazê-lo, sugeriu que poderia pertencer a uma determinada comunidade. Os jurados tiveram 
de fazer perguntas sobre esta história para descobrirem quem ele realmente era. À medida que as pessoas debatiam a sua provável identidade, existia uma forte possibilidade de ocorrer alguma polarização. Tal foi evitado, até certo ponto, quando começámos a incorporar os comentários dos participantes na personagem do Leo, independentemente da sua natureza contraditória. As pessoas (apesar de informadas) não estavam realmente conscientes de que estávamos a utilizar uma "técnica de vigilância" para a criação das personagens, mas ficavam encantadas por ver surgir uma personagem complexa a partir das suas perspetivas. Desta forma, o Leo, inicialmente uma opção pouco popular para herói, tendo recebido poucos votos, tornou-se uma personagem envolvente que refletia as preocupações das pessoas e com quem as pessoas se podiam identificar, como um dos participantes referiu nos comentários:

pensava que era um jogo ... mas não sabia o que esperar. Achei bastante interessante quando o Leo revelou o seu passado duvidoso. Achei que a forma como as pessoas se apresentavam era interessante - fiquei surpreendido por escolher o Leo, mas pareceu-me mais real. (Jogador 1, comentários de um jogador)

Também ficámos surpreendidos com este resultado, especialmente porque a maioria dos participantes eram mulheres com mais de trinta anos e o Leo tornou-se num pai desempregado e ausente. Contudo, também sucede que alguns participantes se sentiam nervosos por partilharem as suas opiniões em público desta forma. Do projeto faziam parte alguns jurados que observavam de fora, queriam que as suas opiniões produzissem efeito, o que era demonstrado pelo seu comportamento de voto, mas não queriam contribuir para a criação das personagens. Fazê-lo poderia levar à criação de um conflito e, no contexto da Irlanda do Norte, esse conflito poderia ter consequências. Assim, neste tipo de projetos, os guionistas precisam de estar conscientes das necessidades tanto dos participantes inativos como dos jogadores ativos. A utilização de uma comunidade imaginada enquanto elemento de construção para o protótipo demonstrou ser extremamente imersiva para os participantes, tendo dado origem a uma forte comunidade de jogadores.

Uma ficção construída com base em comunidades imaginadas - construídas pelas imagens, textos e discursos de um conjunto de pessoas - desenvolve e amplia, deste modo, a ideia de Hugh O'Donnell (1999, p. 10) sobre novelas ou séries dramáticas contínuas enquanto "locais de um processo complexo e contínuo de negociação entre os produtores e os próprios consumidores que ocorre num enquadramento muito mais vasto". Também se assemelha aos defensores do entretenimento educativo (EE), ou novelas educativas que adotaram uma abordagem de ação social, dado que há muito que as novelas são vistas como veículo eficaz de promoção da mudança social. No início dos anos 1970, Miguel Sabido criou um novo género para a televisão mexicana que consistia numa novela de entretenimento educativo, um programa educativo que promovia o desenvolvimento social (Singhal, Cody, Rogers \& Sabido, 2008). Os seus esforços influenciaram muito projetos semelhantes noutros países, tanto na rádio como na televisão e, 
atualmente, na internet. Desde os anos 1980, os criadores de programas têm utilizado esta estratégia como parte da sua campanha de comunicação na América Latina, em África e na Ásia (Singhal, 2006), para promover a paz e a resolução de conflitos. Singhal sugere que esse entretenimento educativo poderia conduzir a transmédia socialmente ativos e, talvez, a uma produção interativa. Deste modo, o projeto $\mathrm{RBH}$ deve muito a essas formas populares de entretenimento e educação, mas uma narrativa negociada não visa necessariamente promover o desenvolvimento social acima de tudo, apesar de tal desenvolvimento estar no centro da estrutura da narrativa. De facto, tal prática poderia ser manipulada por um conjunto de autores para promover mensagens muito diferentes. Desta forma, concordamos com a afirmação de Zuboff (2019, p. 19), segundo o qual o "capitalismo de vigilância não é tecnologia (...) O capitalismo de vigilância baseia-se em algoritmos e sensores, máquinas inteligentes e plataformas, mas não é o mesmo que estes". A forma do projeto e a sua estrutura associada não é o aspeto que promove necessariamente o discurso e a participação democrática, apesar de contribuir em parte para ela e disponibilizar novas formas de envolvimento nesse discurso. Em vez disso, é a intenção do autor e o contexto no qual o autor e o leitor se encontram que são a chave para o sucesso do projeto.

\section{ANÁLISE Do PROTótIPO}

Apesar de um conjunto crescente de evidências que detalham os aspetos negativos da participação em linha e as visões antidemocráticas de alguns intervenientes organizados e altamente motivados no domínio da internet, acreditamos que se trata de algo que é habitual encontrar em fóruns em linha que não são moderados de forma significativa. Uma narrativa negociada é, pela sua própria essência, uma narrativa moderada e em que qualquer contributo pode ser desafiado, pelo que o argumento de Quandt, de que as "formas positivas de participação parecem estar terrivelmente ultrapassadas hoje em dia" (Quandt, 2018, p. 44), é vencido pela utilização de uma abordagem negociada na criação de conteúdos, o que Kligler-Vilenchik designou de "boa participação": "há uma necessidade constante de perceber a boa participação, mas, em vez de uma ideia abstrata que resulta de noções idealistas, devíamos fazê-lo de uma forma empiricamente inspirada pelas práticas de participação reais de pessoas reais (mesmo que poucas)" (Kligler-Vilenchik, 2018, p. 13).

Desta forma, o nosso estudo (que tem por base 40 elementos) reconhece que os participantes eram provenientes, sobretudo, de grupos comunitários e artísticos da Irlanda do Norte, interessados pelas formas como as histórias são contadas e apoiadas. Este facto limita, em alguma medida, o estudo, sendo importante reconhecer que se o storytelling envolvesse um conjunto de participantes mais vasto e com origens diferentes, teria, sem dúvida, sido uma proposta mais difícil e desafiante, dado que teriam surgido mais facilmente preconceitos e outras opiniões. Isto não invalida, contudo, a experiência do protótipo. A participação e os conflitos que ocorreram foram analisados no protótipo e o conhecimento obtido foi utilizado para inspirar trabalhos futuros. 

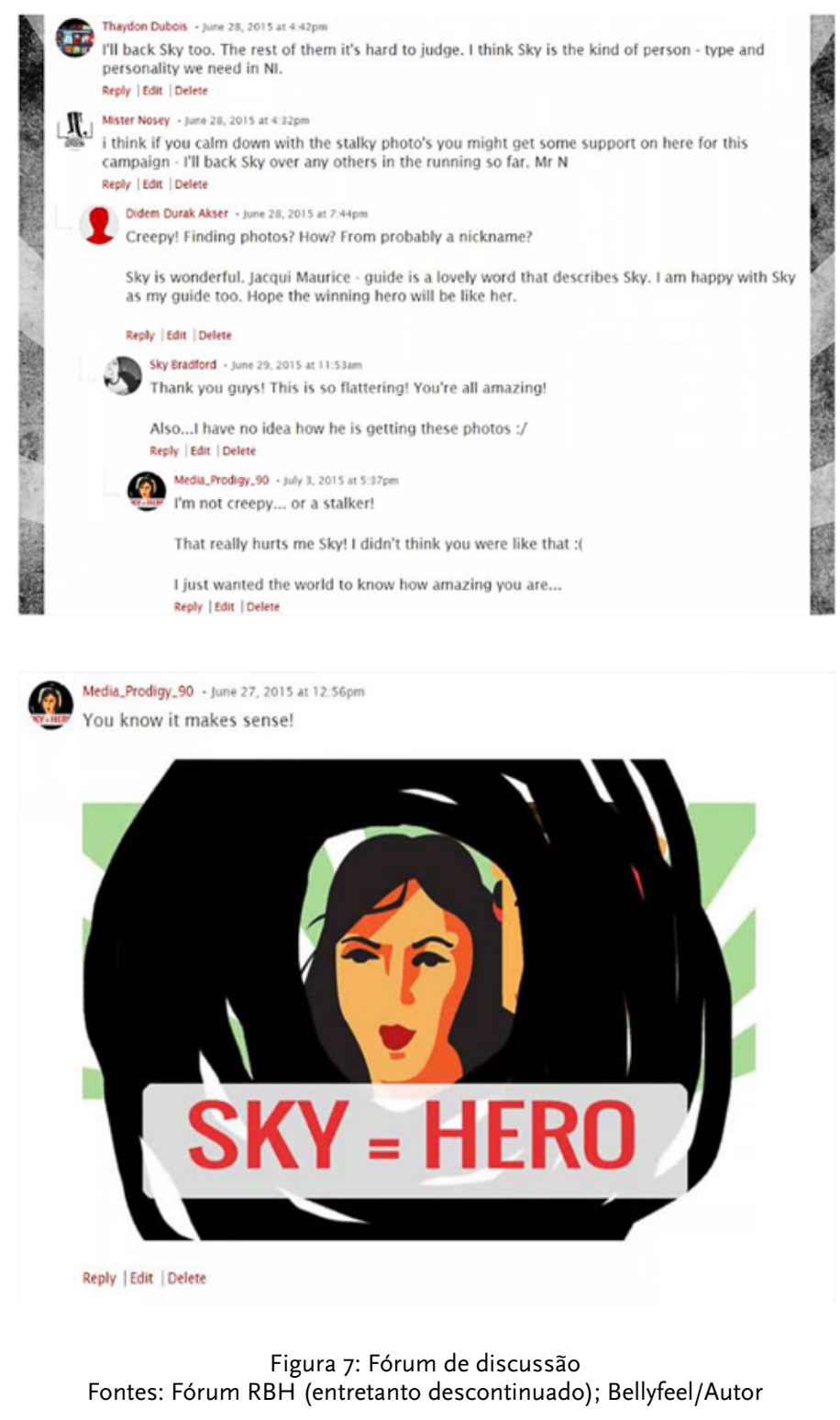

Era fundamental que diferentes comunidades estivessem presentes neste projeto. Dos 40 participantes que aderiram, 27 tinham mais de 30 anos e 13 tinham menos de 30. Vinte e dois eram mulheres e 18 eram homens. A maioria era proveniente de grandes cidades, tais como Belfast ou Derry/Londonderry, mas havia um número surpreendente de pessoas provenientes de pequenas cidades e zonas rurais. Muito poucas pessoas se identificaram como sendo religiosas, mas, das que o fizeram, cinco eram de origem católica e três de origem protestante. Vinte nasceram e cresceram ou viveram na Irlanda do Norte a maior parte da vida, seis não tinham ligação ao local e catorze tinham ligações secundárias, sendo, por exemplo, casadas com alguém local. Em projetos em linha não associados a grandes concessões, este número pode ser considerado uma amostra saudável. Um reduzido número não desvaloriza necessariamente o interesse da informação obtida. Lance Weiler (2015a, 2015b) utilizou grupos de doze participantes para 
testar o seu protótipo Sherlock e defende que pequenos grupos de cinco a seis pessoas são ideais para garantir capacidade de ação e de compreensão do trabalho. Mais importante para nós, tratava-se de uma amostra que representava um conjunto variado de pessoas. Destas 40 pessoas, 10 publicavam regularmente, mas existia um grupo nuclear de cerca de seis pessoas que estavam constantemente envolvidas. Tal significa que a maioria dos participantes desempenhava um papel menos ativo. Mais uma vez, tal pode ser visto de forma negativa, pois um grupo autosselecionado de pessoas apropriaram-se do projeto. Contudo, dado que o grupo nuclear era um grupo muito variado e diversificado de pessoas que, na sua maioria, não se conheciam mutuamente, sugerimos que não foi este o caso.

Talvez seja importante detalhar aqui o que é frequentemente referido como a Regra do 1:9:90, segundo a qual em cada 100 utilizadores da internet, apenas 10\% irá interagir, sendo que os restantes $90 \%$ irão simplesmente ver o conteúdo (McConnell \& Huba, 2006). Desses 10\%, apenas 1\% é suscetível de ser criador de conteúdos. Charles Arthur (2006, s.p.) defende que "não se deve esperar muito do online. Para fazer eco do filme Campo de sonhos, certamente que se o construir, ele virá. O problema, como na vida real, é encontrar quem construa". Embora se sugira que esta dinâmica está a mudar, este projeto encontrou os construtores nessas 10 pessoas, o que representa $25 \%$ do grupo de teste; a maioria dessas pessoas tinha mais de 40 anos, o que constituiu uma verdadeira surpresa, já que habitualmente as pessoas desta faixa etária não são vistas como construtoras de projetos na internet. Outra constatação importante foi que esses construtores eram mais suscetíveis de promover e animar o projeto para os outros que viam. Assim, os construtores incentivaram e apelaram as pessoas que viam a comentar e votar, o que gerou provavelmente uma participação maior. Tal sugere que o facto de se ter um elemento de controlo poderia ser uma preocupação mais crucial do que a participação. Alison Jeffers (2017, p. 209) sustenta, quando escreve sobre a participação na Irlanda do Norte:

apesar do sucesso do Acordo de Belfast no estabelecimento de um governo que partilha o poder, baseado no entendimento da legitimidade das perspetivas unionista e nacionalista, muitas questões permanecem por resolver. Estas incluem "a questão de como lidar com o legado do passado" e o facto de que a "divisão permanece como um infeliz facto da vida". (McKittrick \& McVea, 2012, p. 305).

O trabalho dos argumentistas para cinema, televisão e novos média, desde essa altura, é, em parte, definido pelo facto desses argumentistas terem crescido durante o conflito "The troubles" 4 , sendo o seu trabalho então influenciado por esse período. Pode argumentar-se, como é o caso de Heidemann, quando aborda a literatura pós-Acordo,

\footnotetext{
4 "The troubles" é um termo utilizado frequentemente para referir um conflito que ocorreu na Irlanda do Norte entre as décadas de 1960 e 1990. O conflito, embora seja frequentemente visto como um conflito religioso (entre Católicos e Protestantes), foi principalmente uma luta política alimentada por factos históricos. Os Unionistas/Lealistas queriam que a Irlanda do Norte se mantivesse no Reino Unido e os Nacionalistas/Republicanos Irlandeses queriam unir-se à Irlanda.
} 
que o seu trabalho "se preocupa com identidades de sujeitos suspensos entre um passado 'repressivo' e um futuro 'progressivo' e que o trabalho daí resultante não tenta 'sarar' nem 'resolver' o dilema político da Irlanda do Norte" (Heidemann, 2016, p. 251).

Em vez disso, sugere que a literatura pós-Acordo (novelas, poesia e teatro) se preocupa em "reestruturar, reformular e, principalmente, diagnosticar a absorção passiva do passado violento do país por um 'futuro acordado' e que o 'passado violento não configura necessariamente o tom dominante das suas escritas'” (Heidemann, 2016, p. 251).

$\mathrm{O}$ design e a escrita do RBH demonstram traços semelhantes. Talvez essa absorção passiva não só do conflito "The Troubles", mas também das práticas dos média digitais, fosse uma preocupação para muitos participantes do $\mathrm{RBH}$ ?

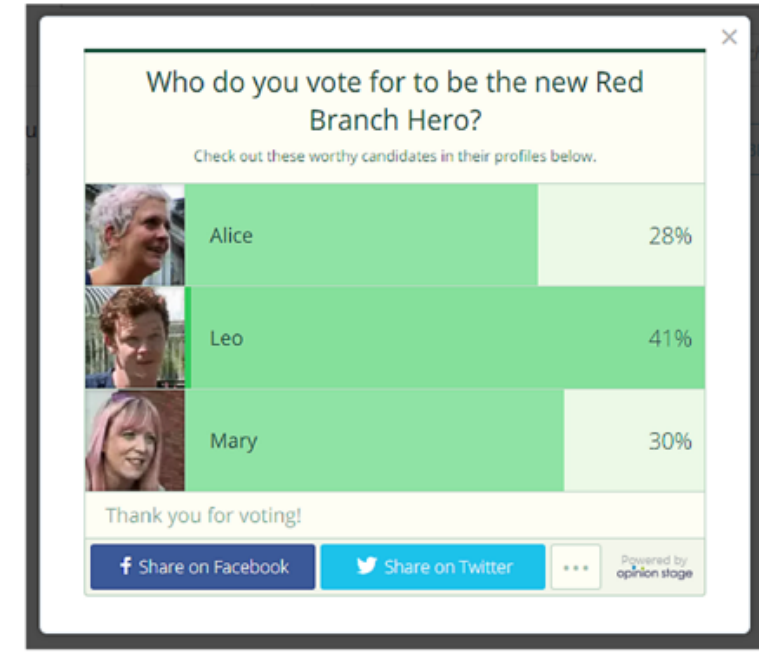

Figura 8: Escolha dos candidatos

Fontes: Inquérito RBH (entretanto descontinuado); Bellyfeel/Autor

Heidemann fala de teóricos (Nordin \& Holmsten, 2009) que consideram a Irlanda como uma sociedade pós-colonial e aplicam o conceito de liminaridade como "um local de negociação e re-identificação" (Heidemann, 2016, p. 8) e um estado capacitante. Discordando de tal posição, sugere que o que caracteriza a Irlanda do Norte é um estado de "liminaridade negativa" (Heidemann, 2016, p. 10), uma condição incapacitante que resiste ao virar de página. Contudo, não vê este facto como uma preocupação negativa ou uma condição patológica da Irlanda do Norte do pós-Acordo. Em vez disso, sugere que "os escritores do 'pós-Acordo' se preocupam principalmente com os problemas privados das suas personagens literárias em oposição à leitura discursiva das próprias estruturas políticas" (Heidemann, 2016, p. 51).

As nossas preocupações também foram conduzidas pela tentativa de obter um entendimento sobre a forma como as pessoas foram influenciadas por estas experiências. Encontrar uma forma que fosse capaz de acomodar uma série de opiniões foi determinante na implementação de tal projeto. Deste modo, a conceção do projeto tornou-se numa mistura de formas populares que são capazes de levar ideias complexas a 
audiências mais vastas, para além do desenvolvimento de personagens complexas, que exemplificam melhor as preocupações atuais das pessoas que vivem na Irlanda do Norte. Jogar neste espaço significa que todos fomos capazes não só de criticar e analisar personagens, mas também de olhar novamente para algumas coisas que significam ser norte-irlandês. No entanto, neste contexto, estamos conscientes do comentário de Jeffers, segundo o qual "a participação não constitui, por si só, o garante da necessária redistribuição de autoridade que pode conduzir à mudança social positiva" (Jeffers, 2017, p. 210). Como resultado, a participação, definida como a disponibilização de acesso, não foi, per se, o principal objetivo do projeto. Em vez disso, o projeto visava criar um tipo de participação que promovia e desafiava a autoridade dos autores. Ao abordar a participação em teatro comunitário em Belfast, afirma ainda que "o valor de pensar sobre a autoridade é que nos permite identificar e examinar diferentes tipos de poder e o papel do conhecimento e das relações no desenvolvimento destes" (Jeffers, 2017, p. 218). Tal prática foi fundamental no projeto $\mathrm{RBH}$ e os seus participantes contestaram frequentemente as ações dos autores e os enredos sugeridos, inventando os próprios para os substituir.

Heidemann (2016, p. 192) sugere que só na década de 1970 é que a "colusão estética entre arte e política emergiu como característica distintiva do teatro contemporâneo norte-irlandês". Sugere que produções mais recentes, como Pumpgirl (2006) de Abbie Spallen e This other city (2010) de Daragh Carville, adotam o "modelo de trabalho de integralidade" (Heidemann, 2016, p. 192) de Stewart Parker e aplicam-no a uma nova situação política: as armadilhas da política neoliberal na Irlanda do Norte. Como tal, as peças que analisa "fornecem um comentário provocador sobre o edifício neoliberal 'progressivo' do Estado-nação” (Heidemann, 2016, p. 193). O RBH espelha esta prática. Os nossos objetivos vão, assim, para além da ideia de "alargar a participação" a audiências, estando associados a ideias de "democracia cultural" (Kelly, Locke \& Merkel, 1986, s.p.) que destacam uma mudança no poder entre o artista/autor e o participante (Webster \& Buglass, 2005, p. 21). Jack Linchuan Qui (citado em Allen et al., 2014, p. 1133), que estudou exaustivamente os utilizadores chineses de internet, não vê correlação entre enquadramentos ascendentes inclusivos e a nivelação das estruturas políticas de controlo, sugerindo que "em vez disso, as estruturas de controlo parecem ter ganho com a nova riqueza do conteúdo gerado pelo utilizador, que beneficia mais do que ninguém as entidades competentes". Não faria sentido participar na construção de uma websérie online negociada e participativa se o propósito por detrás dela fosse "gerar um tipo diferente de 'conflito', certamente menos violento, mas que aponta para novas formas de violência exercidas pela negação retórica do Acordo relativamente ao passado sectário e à sua agressiva campanha neoliberal" (Heidemann, 2016, p. 4).

Tal processo seria uma participação sem capacidade de ação e de controlo, e a mera participação seria apenas acesso e interação. Não é isto que esta investigação recomenda. Os participantes do $\mathrm{RBH}$ eram verdadeiros proprietários daquilo que era criado no projeto utilizando uma abordagem crítica na criação da história, apesar do seu reduzido número. 


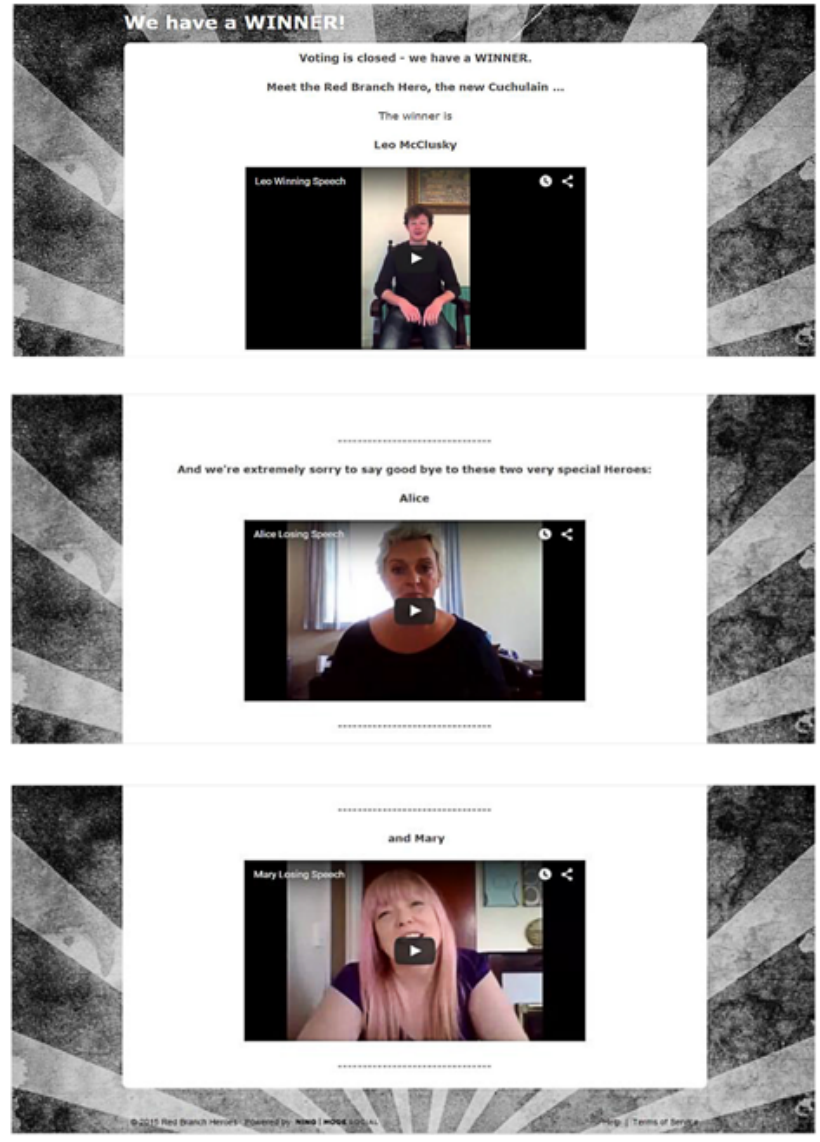

Figura 9: O vencedor Fonte: Bellyfeel/Autor

No RBH, apesar de o staff responsável pela produção ter um maior controlo e entendimento dos processos em jogo, encontrava-se numa posição semelhante aos membros da audiência, na medida em que "aceitavam que a participação genuína comporta riscos e potencialidades: esta implica vulnerabilidade da parte dos atores e participantes, dado que ambas as partes se abrem a experiências e resultados inesperados" (Freshwater, 2011, p. 409).

Preparar essa tarefa numa sociedade polarizada complica ainda mais esse processo e foi necessário dialogar para definir de que forma esta tarefa seria realizada. Alguns jurados pretendiam mais orientações nesta tarefa: "penso que o eleitorado tem de estar adequadamente envolvido na história/contexto/problemas. (...) a fase onde era suposto 'ajudar o herói que escolhemos a desenvolver a sua história' era confusa. Não percebi o que era suposto fazer" (Jogadores 2 e 3, comentários dos jogadores).

Não fomos suficientemente claros com os nossos participantes sobre com que duração e negociação as nossas personagens seriam criadas. Criámos um processo e assumimos que este processo seria evidente para os participantes e iria atingir o resultado pretendido. O processo criou, de facto, personagens completas através dos estudos e da promoção dos jurados, mas deveríamos ter sido claros quando esse processo ficou 
completo. Equivocadamente, conduzimos o processo a um fim abrupto, o que teve o efeito de garantir que as pessoas queriam mais, mas também lhes provocou alguma solidão, pois sentiam falta da comunidade unida que se criou. Uma falta de envolvimento da parte dos orquestradores levou muitas vezes os jurados a colmatar as lacunas e a fazer a história avançar e assumi-la como sua. Talvez devêssemos ter envolvido os participantes no fim do trabalho. Apesar de a discussão no sítio sobre a Irlanda do Norte ser de baixa intensidade e muito tentadora, as possíveis personagens bem-sucedidas pareciam incorporar as características negociadas dessa discussão. Esta é, talvez, a maior lição do ponto de vista da escrita - o controlo e a coesão da história foi menos merecedor de preocupação para os nossos participantes do que os gurus (Gomez, 2011) do transmédia nos levariam a pensar e os participantes são capazes de perceber de forma mais aprofundada o que é necessário numa história, mesmo que não saibam necessariamente como é que eles próprios poderão criar isso.

Recebemos muito poucos comentários sobre a forma como este tipo de projeto poderá ser "eficaz" no contexto da Irlanda do Norte. Em geral, todos os participantes evitaram responder a esta questão e alguns até a eliminaram dos seus formulários. É difícil especular porquê. Mais uma vez, vale a pena considerar esta falta de participação. Talvez se deva às formas como os filmes e a televisão têm sido utilizados relativamente ao "The Troubles". O estudo de Lance Pettitt (2000) sobre documentários dramáticos sugere que, apesar de esses filmes se basearem em investigação jornalística, utilizam as convenções dos filmes de ficção para contarem as suas histórias e mediarem o mundo real. Teríamos talvez obtido uma melhor resposta se tivéssemos feito esta questão durante a história e não depois. As pessoas sentir-se-iam mais capazes de falar no ambiente ficcional.

O filme Sunday (2003), de Jimmy McGovern, não faz qualquer tentativa de imitar o estilo do documentário e é claramente apresentado como uma versão ficcional. No entanto, é baseado nas histórias e nas conversas que aquele teve com muitas pessoas e, em certos aspetos, é o culminar dessa atividade. McGovern medeia a verdade dos factos através de uma história que ele próprio criou. $\mathrm{O}$ mesmo acontece com o processo utilizado pelo $\mathrm{RBH}$, só que esta abordagem vai mais longe e pede que as vítimas e as famílias não só forneçam as histórias, mas também respondam e contribuam para a verdade mediaticamente produzida, num fórum público. Embora se configure mais como um drama do que como um documentário, o programa pede à audiência que jogue com estes conceitos. Como sugere Sarah Edge (2009, p. 185), "o documentário dramático é um género especialmente poderoso, no qual os sinais de realismo e ficção se misturaram". O trabalho do RBH não só mistura o mundo real e ficcional para representar o ambiente atual da Irlanda do Norte, como também utiliza as formas mais contestadas de mundos semirreais ou semifictícios da reality television, um género habitualmente associado à atribuição de características depreciativas a pessoas comuns. Neste caso, a intenção passava por utilizar as convenções do género para fins mais positivos. Os elementos voyeurísticos associados à reality television e redes sociais foram utilizados para motivar abordagens de investigação à conceção da história. Resumidamente, perguntámos às 
pessoas o que era importante para as suas vidas enquanto jogávamos um jogo baseado numa história que integrava essas ideias.

A relação dinâmica entre o autor e a audiência criou um forte sentimento de pertença a este projeto e permitiu que as pessoas de ambas as comunidades pudessem participar ativamente. Houve um surpreendente consenso sobre o tipo de herói necessário ao mundo moderno e que atributos esse herói deveria ter, como demonstra o tópico de discussão do projeto.

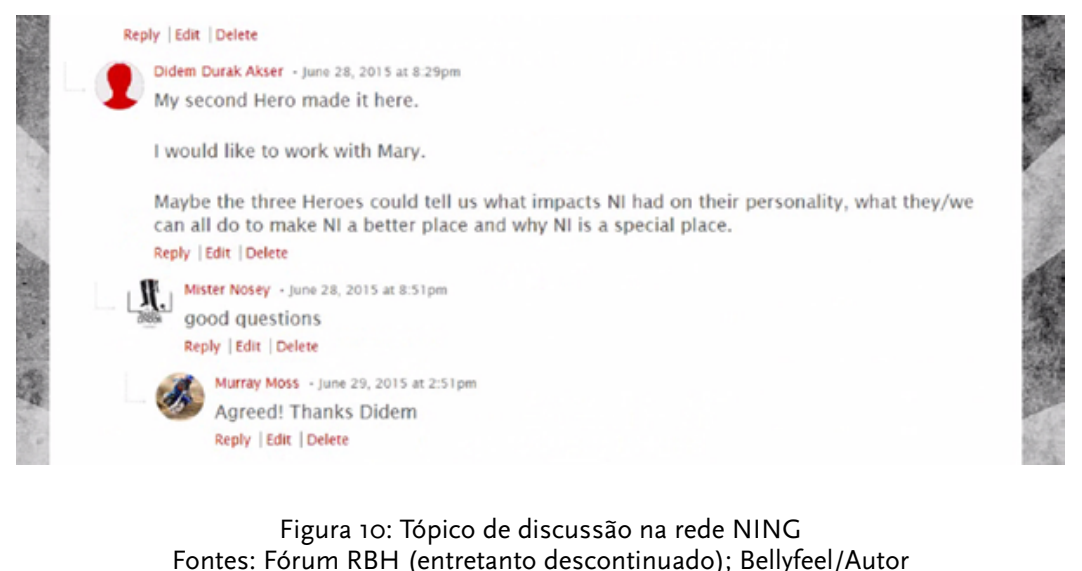

Existia uma vontade de compreender a complexidade do comportamento humano e não de tomar partido. Quando confrontados com informações difíceis, os jurados tentaram ver o lado positivo, ultrapassar descrições de personagens estereotipadas e passar a um processo em que se revela uma personalidade profunda. Esse resultado satisfatório poderia sugerir que os elementos performativos e de jogo foram cruciais para a construção de uma narrativa convincente e que a narrativa criada não sofreu o impacto negativo desses elementos participativos. Contudo, caso este projeto fosse mais desenvolvido, incluiríamos eventos presenciais nas nossas práticas transmédia e interativas, para que as pessoas se pudessem conhecer e partilhar experiências juntas em espaços neutros, nos quais os elementos da história pudessem ser ampliados e desenvolvidos, para que a experiência online pudesse ser alargada às suas próprias vidas.

\section{Conclusão}

Deste modo, é necessário reconhecer que a participação per se não resulta automaticamente numa prática democrática ou numa efetiva produção criativa. Também não podemos ignorar as competências e a experiência que o autor traz ao processo de criação. Na nossa opinião, precisamos de recalibrar e repensar como e por que motivo oferecemos oportunidades de participação, para que possamos assegurar-nos de que essas oportunidades resultem em criação efetiva. Neste sentido, não se trata de quantas pessoas contribuem, quanto e com que frequência, mas sim da qualidade participativa da sua contribuição e dos termos em que esta é incluída, recompensada e reconhecida. 
Por estes motivos, consideramos que a expressão "narrativa negociada" é eficaz neste contexto, pois admite que o processo interativo e participativo é um processo consultivo, que resulta numa síntese de histórias produzidas por todas as partes envolvidas no projeto. Como Carpentier aponta, a verdadeira questão é a de controlo e poder: "as lutas sobre a distribuição de poder na sociedade em áreas como os média, as artes e o desenvolvimento, bem como as tentativas de tornar essa distribuição mais equitativa, são aquilo que define a participação" (Carpentier citado em Allen et al., 2014, p. 1132).

Desta forma, os transmédia interativos e a tecnologia que os oferece não proporcionam uma revolução no storytelling propriamente dita. Contudo, a sua liminaridade enquanto forma contribui para oportunidades que podem ser utilizadas para possibilidades imersivas. Acima de tudo, esta liminaridade e capacidade de gerar múltiplas vozes, geradas através do processo participativo que oferece ao leitor/utilizador/jogador maior poder e controlo, também contribuem para uma sociedade mais democrática e descentralizada. Aqui é dada importância à participação, porque nos afasta das difíceis dicotomias que suportam conflitos (violentos), demonstrando que as muitas zonas cinzentas e as pluralidades que caracterizam as sociedades contemporâneas podem coexistir com sentimentos de pertença.

Como sempre, depende muito de quem controla essas oportunidades. Uma narrativa negociada reconhece as formas em que as narrativas podem ser desviadas para promover determinado ponto de vista e sugere que a tomada de decisão discursiva enquanto elemento central da criação participativa da história reduz a probabilidade de tal acontecer. Também reconhece os problemas criados pelo "capitalismo de vigilância" e, apesar de utilizar técnicas semelhantes, mas não através de máquinas, sugere que esses métodos podem ser utilizados para efeitos mais positivos, caso as relações de poder inerentes sejam transparentes, claras e dinâmicas. Oferecer oportunidades em que a vida real e a ficção se sobrepõem ajuda a desenvolver comunidades online em que podem ser criadas relações fortes entre grupos diversos de pessoas. Como resultado, este estudo e este artigo colocam a possibilidade de que nem tudo está perdido no que se refere aos aspetos benéficos da participação. Analisemos mais aprofundadamente o potencial da produção interativa para compreendermos melhor os seus benefícios e dificuldades.

Tradução: A Inovtrad - Tradução, Formação e Serviços Unipessoal, Lda.

\section{REFERÊNCIAS}

Abercrombie, N. \& Longhurst, B. (1998). Audiences. Londres \& Thousand Oaks: Sage.

Alderman, N. (2015, 13 de outubro). The first great works of digital literature are already being written: they're called games. The Guardian. Retirado de https://www.theguardian.com/technology/2015/oct/13/ video-games-digital-storytelling-naomi-alderman 
Allen, D., Bailey, M., Carpentier, N., Fenton, N., Jenkins, H., Lothian, A., Qiu, J. L., Schäfer, M. T. \& Srinivasan, R. (2014). Participations: dialogues on the participatory promise of contemporary culture and politics. International Journal of Communication, 8, 1129-1151.

Anderson, B. (1983). Imagined communities: reflections on the origin and spread of nationalism. Londres: Verso Books.

Arendt, H. (1958). The human condition. Chicago: University of Chicago Press.

Arthur, C. (2006, 20 de julho). What is the 1\% rule? The Guardian. Retirado de https://www.theguardian.com/ technology/2006/jul/20/guardianweeklytechnologysection2

Barthes, R. (2001). The death of the author. In J. Caughie (Ed.), Theories of authorship (pp. 208 -213). Londres: Routledge.

Berger, J. (1979). Ways of seeing, Londres: Pelican/Penguin Books.

Cooke, B. \& Kothari, U. (Eds.) (2001). Participation: the new tyranny? Londres: Zed Books.

Coulter, C. \& Shirlow, P. (2019). From the "Long War" to the "Long Peace": an introduction to the special edition. Capital and Class, 43(1), 3-21. https://doi.org/10.1177/0309816818818084

Dawson, G. (2019). Storytelling in "post-conflict" times: narrative, subjectivity and experience in communitybased peacebuilding. In S. Lehner \& C. McGrattan (Eds.), The promise of peace in Northern Ireland. Manchester: Manchester University Press.

Dena, C. (2009). Transmedia practice: theorising the practice of expressing a fictional world across distinct media and environments. Tese de doutoramento, Universidade de Sidney, Sidney, Austrália.

Edge, S. (2009). Negotiating peace in Northern Ireland: film, television and post-feminism. Visual Culture in Britain, 10(2), 177-187. https://doi.org/10.1080/14714780902925051

Foucault, M. (1977). Language, counter-memory, practice. Nova lorque: Cornell University Press.

Foucault, M. (1980). Power/knowledge. Nova Iorque: Pantheon Books.

Freshwater, H. (2011). "You say something": audience participation and The Author. Contemporary Theatre Review, 21(4), 405-409. https://doi.org/10.1080/10486801.2011.610308

Gaver, B., Dunne, T. \& Pacenti, E. (1999). Design: cultural probes. Interactions, 1(1), 21-29.

Gomez, J. (2011). Storyworlds: the new transmedia business paradigm. Comunicação apresentada no evento "Tools of Change for Publishing conference (TOC)", Nova Iorque.

Habermas, J. (1991). The structural transformation of the public sphere. Cambridge, Massachusetts: MIT Press.

Heidemann, B. (2016). Post-agreement Northern Irish literature: lost in a liminal space? Londres: Palgrave Macmillan.

Jeffers, A. (2017). Authority, authorisation and authorship. In A. Harpin \& H. Nicholson (Eds.), Performance and participation: practices, audiences, politics (pp. 209-229). Londres: Palgrave Macmillan.

Jenkins, H. (2006). Convergence culture. Nova lorque: New York University Press.

Jenkins, H. (2012). Textual poachers: television fans and participatory culture, updated twentieth anniversary edition. Nova lorque: Routledge. 
Kelly, O., Lock, J. \& Merkel, K. (1986). Culture and democracy: the manifesto. Londres: Comedia.

Kligler-Vilenchik, N. (2018). Why we should keep studying good (and everyday) participation: an analogy to political participation. Media and Communication, 6(4), 111-114. http://dx.doi.org/10.17645/mac. v6i4.1744

Le Hunte, B. \& Golembiewski, J. (2014). Stories have the power to save us: a neurological framework for the imperative to tell stories. Arts and Social Science Journal, 5(2), 73-76. http://dx.doi. org/10.4172/2151-6200.1000073

Lutz, C. \& Hoffmann, C. (2017). The dark side of online participation: exploring non-, passive and negative participation. Information, Communication Q Society, 20(6), 876-897. https://doi.org/10.1080/136911 $8 X .2017 .1293129$

Madden, D., Cadet-James, Y., Atkinson, I. \& Watkin Lui, F. (2014). Probes and prototypes: a participatory action research approach to codesign. CoDesign, 10(1), 31-45. https://doi.org/10.1080/15710882.2014.8 81884

Manovich, L. (2001). The language of new media. Cambridge, Massachusetts: MIT Press.

Mattelmaki, T. (2005). Applying probes: from inspirational notes to collaborative insights. CoDesign, 1(2), 83102. https://doi.org/10.1080/15719880500135821

McConnell, B. \& Huba, J. (2006, 3 de maio). The 1\% Rule: charting citizen participation. Church of the Customer Blog. [Post em blogue]. Retirado de https://web.archive.org/web/20100511081141/http://www. churchofthecustomer.com/blog/2006/05/charting_wiki_p.html

McGonigal, J. (2011). Reality is broken: why games make us better and how they can change the world. Nova lorque: Penguin Press.

McKittrick, D. \& McVea, D. (2012). Making sense of the troubles: a history of the Northern Ireland conflict. Londres: Penguin.

McQuaid, S. (2012). Trailblazers and cassandras: other voices in Northern Ireland. Nordic Irish Studies, 2(2), 71-93.

Miessen, M. (2010). The nightmare of participation. Berlim: Sternberg.

Millard, K. (2014). Screenwriting in a digital era. Hampshire: Palgrave Macmillan.

Nordin, G. \& Holmsten, E. (2009). Liminal borderlands in Irish literature and culture. Pieterlen: Peter Lang.

O'Donnell, H. (1999). Good times, bad times: soap operas and society in Western Europe. Londres \& Nova Iorque: Leicester University Press.

O'Neill, C. (1995). Drama worlds. Portsmouth: Heinemann.

Ofcom, The Office of Communications. (2013). Communications market report: Northern Ireland. Retirado de https://www.ofcom.org.uk/_data/assets/pdf_file/0021/40692/2013_cmr_northern_ireland.pdf

Pettitt, L. (2000). Screening Ireland. Manchester: Manchester University Press.

Phillips, A. (2012, 3 de julho). Transmedia storytelling, fan culture and the future of marketing. Retirado de http:// knowledge.wharton.upenn.edu/article/transmedia-storytelling-fan-culture-and-the-future-of-marketing/

Quandt, T. (2018). Dark participation. Media and Communication, 6(4), 36-48. http://dx.doi.org/10.17645/ mac.v6i4.1519 
Rose, F. (2012). The art of immersion. Nova lorque: W.W Norton \& Company.

Ryan, M. (2001). Narrative as virtual reality: immersion and interactivity in literature and electronic media? Baltimore: John Hopkins University Press.

Said, E. (1978). Orientalism. Nova Iorque: Pantheon Books.

Singhal, A. (2006). Popular media and social change: lessons from Peru, Mexico, and South Africa. The Brown Journal of World Affairs, XIII(2), 259-269.

Singhal, A., Cody, M., Rogers, E. \& Sabido, M. (2008). Entertainment-education and social change. Londres: Taylor and Francis.

Watson, T. (2001). Beyond managism: negotiated narratives and critical management education in practice. British Journal of Management, 12(4), 385-392. https://doi.org/10.1111/1467-8551.00216

Webster, M. \& Buglass, G. (2005). Finding voices, making choices: creativity for social change. Nottingham: Educational Heretics Press.

Weiler, L. (2015a). Sherlock Holmes and the internet of things. Retirado de http://lanceweiler.com/ sherlock-holmes-the-internet-of-things/

Weiler, L. (2015b). Sherlock. Retirado de https://sherlock.hackpad.com/Sherlock-Prototype-5215-icYVe3DgIXW

Zipes, J. (2011). The meaning of the fairy tale within the evolution of culture. Marvels Q Tales, 25(2), 221-243.

Zuboff, S. (2018). The age of surveillance capitalism. Londres: Profile Books.

Zuboff, S. (2019, 20 de janeiro). Entrevista com John Naughton. The Observer, pp. 18-21.

\section{NOTAS BIOGRÁFICA}

Anna Zaluczkowska é Leitora e Diretora de Guionismo na The Northern Film School, na Universidade Leeds Beckett, no Reino Unido. Venceu diversos prémios enquanto argumentista e realizadora. Desenvolve investigação sobre storytelling, com particular interesse nas dinâmicas participativas.

ORCID: https://orcid.org/oooo-0003-3862-4460

Email: Anna.Zaluczkowska@leedsbeckett.ac.uk

Morada: Northern Film School, Leeds Beckett University, 1 Millennium Square, Leeds LS2 5AD, Reino Unido

* Submetido: 24/01/2019

* Aceite: 30/03/2019 